\title{
Los rasgos generales de la amigable composición en el ordenamiento colombiano*
}

\author{
The general features of the friendly composition in the colombian order
}

\author{
Mònica María Fuentes Mancipe** \\ Diego David Barragán Ferro ***
}

\begin{abstract}
* Producto resultado de Investigación del Proyecto “ Creación y desarrollo de un laboratorio de análisis y formación legislativa, soportado en el espacio UGC de la Plataforma ARCA" financiado por el Fondo Julio Cesar García, Universidad La Gran Colombia.

** Doctoranda en derecho romano, teoría de los ordenamientos y derecho privado del mercado. Magister en Derecho comercial Internacional y Especialista en Derecho Comercial. Docente Investigador de la Universidad La Gran Colombia. Contacto: monica. fuentes@ugc.edu.co ORCID: 0000-0002-3695-8144.

*** Doctorando en Derecho Magíster y especialista en Derecho privado y económico. Docente Investigador de la Universidad La Gran Colombia. Contacto: diego.barragan@ugc.edu.co ORCID: 0000-0003-3818-7299.
\end{abstract}

Fecha de recepción: junio de 2020

Fecha de aprobación: diciembre de 2020

Para citar este artículo / To reference this article

Fuentes, MM; Barragán, D.D (2020) Los rasgos generales de la amigable composición en el ordenamiento colomiano. Inciso, 22(1) ; 161-181.

\begin{abstract}
Resumen
DOI: http://dx.doi.org/10.18634/incj.22v.2i.1068

Una de las grandes necesidades del ser humano, es la de lograr convivir con sus semejantes y establecer relaciones de comunicación; que en algunos casos pueden propiciar la configuración de conflictos como una consecuencia directa de la interacción social que surge en la sociedad como una muestra de los diversos intereses individuales y sociales de los seres humanos por encima del interés general. Conflictos que indudablemente pueden ser solucionados en la actualidad a través de métodos alternativos para la solución de conflictos como la amigable composición, siendo entonces el interés de este artículo, el presentar su concepto, normativa, procedimiento y el papel de las partes y del amigable componedor en la búsqueda de soluciones efectivas y conciliables mediante la justicia alternativa. Pues es, necesario recalcar que este método es un refuerzo para el acceso a la justicia, en él se otorgan funciones jurisdiccionales temporales a particulares tendientes para la superación de conflictos en un escenario diferente al judicial, en donde la voluntad de las partes y el principio de la autonomía de la voluntad contractual es fundamental para su desarrollo
\end{abstract}

Palabras clave: Acuerdo bilateral, justicia, contratos, conflicto social, resolución de problemas. 


\section{Abstract}

One of the great needs of human beings is to be able to live with their peers and establish communication relationships; that in some cases can lead to the configuration of conflicts as a direct consequence of the social interaction that arises in society as a sample of the various individual and social interests of human beings above the general interest.

Conflicts that undoubtedly can be solved at present through alternative methods for the resolution of conflicts such as the friendly composition, being then the interest of this article, in terms of its concept, regulations, procedure and the role of the parties and the friendly composer in the search for effective and reconcilable solutions to different controversies in a different scenario from the judicial one, where the will of the parties and the principle of the autonomy of the contractual will is fundamental for its development.

Keywords: Agreement, justice, administration of justice, contract, administration of justice, conflict, problem solving.

\section{Introducción}

Con frecuencia, las diferencias entre los seres humanos suelen ser dirimidas a partir de la configuración de un estado de armonía necesario, el cual además de asegurar tranquilidad debe proporcionar a cualquier ciudadano el convivir pacíficamente en una sociedad, de ahí que desde tiempos remotos como ( Gierke, Garcia, 1995) hayan concebido diversas formas de mantener la cordialidad, la paz y la sana convivencia entre los seres humanos, ya sea desde la forma de gobierno, el reconocimiento de derechos y de las obligaciones de los particulares, por medio de la administración de justicia como un medio facilitador para la solución de controversias.

Dicho lo anterior, el Estado colombiano para mantener la sana convivencia, desde la Constitución política ha garantizado a todos los ciudadanos el derecho al acceso de la administración de justicia, el cual se concibe desde la función pública encargada de prestar el servicio público de administrar la justicia de manera gratuita, conforme a la ley, al derecho sustancial, principalmente en cabeza del Estado o de un tercero delegado por aquel para tal fin, tal como lo establece el artículo 228 y 229 de la Constitución Política.

Bajo este contexto, los Métodos alternativos de solución de conflictos (MASC) tienen el propósito de revestir e instituir a los particulares funciones jurisdiccionales y transitorias para acelerar la resolución de conflictos sin la intervención del juez o el árbitro, por medio de métodos como la transacción, la conciliación y la amigable composición, entre otros, cuyo propósito principal, además, de resolver los conflictos es el de garantizar a cualquier ciudadano el acceso a la justicia de manera pronta, célere y especializada. 
Por lo expuesto, la amigable composición, entre otros, en la actualidad puede considerarse como un mecanismo idóneo para encontrar una solución a un conflicto que haya surgido entre dos o más partes, ya que a través de un amigable componedor, quien actúa como un tercero imparcial con ciertos conocimientos especializados a través de la figura del mandato de las partes inmersas en la controversia, las conduce a reflexionar y conciliar como una solución pertinente y muy acorde con la consolidación de la armonía y la cohesión social, con profundo respeto de la dignidad humana, la solidaridad, la equidad, la justicia y la ley.

La necesidad de la existencia de instituciones que desarrollen actividades judiciales accesorias a la justicia formal, recae principalmente en este tipo de entes que desarrollen principios justos y equitativos frente aspectos sociales tan importantes como el mantenimiento de la seguridad, el orden y la paz; considerando problemas como los escasos recursos económicos, la existencia de conflictos y la necesidad de proteger derechos y necesidades básicas e inmediatas de los ciudadanos que en algunos casos impiden el derecho al acceso a la justicia de los ciudadanos, lo cual entonces resalta la importancia de instaurar y utilizar los MASC para tales fines.

De donde se infiere entonces que la amigable composición como un método alternativo para la solución de conflictos permite, en cierta medida, a un ciudadano el derecho de acceder a la justicia mediante la búsqueda de una solución en un conflicto de interés particular y/o general por medio de un amigable componedor que como solución a la controversia implementa estrategias de conciliación y arreglo directo, que no solo dan solución a un problema, sino que a su vez restauran la estabilidad del orden jurídico, la convivencia pacífica y la garantía de los derechos del ciudadano de una manera razonable sin ser contrario a lo dispuesto por el legislador y el derecho sustancial.

\section{Materiales y métodos}

Esta investigación tuvo un enfoque descriptivo y cualitativo, pues desde la revisión normativa, jurisprudencial y doctrinal, se reflexiona sobre los rasgos generales de la amigable composición como un método alternativo de solución de conflictos, que garantiza por parte del Estado y de un tercero delegado por los particulares el acceso a la administración de justicia.

En consecuencia, esta descripción utilizo como método el análisis del discurso, el cual según Hernández, Fernández \& Baptista (1991)tiene como enfoque principal es el identificar y especificar respecto a la amigable composición sus características generales en cuanto a sus antecedentes normativos, su concepto actual, el papel de las partes y las atribuciones y facultades del amigable componedor conforme a la ley, la doctrina y las decisiones más relevantes sobre su implementación como método alternativo especializado para la administración de justicia. 


\section{Consideraciones teóricas}

La evolución normativa de la amigable composición y sus principales antecedentes

Los antecedentes normativos de la amigable composición encuentran un primer asentamiento en el artículo 677 del Decreto 1400 de 1970 del Código de Procedimiento Civil Colombiano, artículo derogado posteriormente por el artículo 55 del Decreto 2279 de 1989; y el cual, en todo caso definía a la amigable composición como la posibilidad de recurrir a un tercero para la resolución de un conflicto.

Por lo que podría inferirse para aquella época, que los efectos de la amigable composición eran meramente contractuales (de acuerdo con el artículo 1602 del Código Civil), sin efectos de la cosa juzgada como por el contrario sucede en la transacción otro método alternativo para la solución de conflictos.

Sin embargo, resulta importante señalar que para que la amigable composición pueda instaurarse, entre las partes en conflictos, debe existir la voluntad, siendo entonces esta voluntad manifestada por el consentimiento a través del principio de la autonomía de la voluntad contractual, el cual se enmarca en: "Pilares inherentes al hombre como la libertad y la moral, que constituyen la voluntad del hombre para desarrollar comportamientos sociales". (Ángel , 2016, p. 85).

Lo anterior de conformidad a que el principio de la autonomía de la voluntad contractual puede entenderse como el: "Poder atribuido a la voluntad respecto de la creación, modificación y extinción de las relaciones jurídicas, que indudablemente se referirá a la voluntad de uso, goce y disposición de poderes, facultades y derechos subjetivos" (Hernández F \& Guerra C, 2012, p. 30) como en este caso el acudir por la voluntad de las partes en una controversia a la amigable composición.

Posteriormente, la amigable composición fue consagrada por los artículos 49,50, 51 y 52 del Decreto 2279 de 1989, en donde sobre el particular el artículo 52 de tal estatuto normativo la definió como:

La expresión de la voluntad de someterse a la amigable composición, se consignará por escrito que deberá contener:

1. El nombre, domicilio y dirección de las partes.

2. Las cuestiones objeto de la amigable composición.

3. El nombre o nombres de los amigables componedores cuando las partes no hayan deferido su designación a un tercero.

4. El término para cumplir el encargo, que no podrá exceder de treinta (30) días (Decreto 2279 de 1989 s.p ) 
Teniendo en cuenta las primeras definiciones normativas de la amigable composición, se puede advertir que en el periodo previo a la Constitución Nacional de 1991, la normatividad relativa a este método estaba unida a la del método alternativo de la conciliación, al punto que este último se concebía como la iniciativa y voluntad de tan solo una de las partes para acceder a este tipo de métodos, lo cual es errado, ya que conforme a lo anterior y al principio básico del compromiso o del pacto compromisorio, debe existir para el uso del método de la amigable composición el acuerdo de voluntades de ambas partes.

En tal sentido, es necesario afirmar que en caso contrario la iniciativa de una sola de las partes para acudir a la jurisdicción no se entenderá mediante el uso de un método alternativo para la solución de conflictos, pues al solo requerir la fuerza y la legitimación de una de las partes para iniciar cualquier tipo de acción en cabeza de una de una sola de las partes no existirá voluntad ni acuerdo entre ellas, ni la manifestación común del principio de la autonomía de la voluntad contractual.

Más adelante, la Constitución Política consagra en su artículo 116 inciso 4:

Los particulares pueden ser investidos transitoriamente de la función de administrar justicia en la condición de conciliadores o en la de árbitros habilitados por las partes para proferir fallos en derecho o en equidad, en los términos que determine la ley (Constitución Política de Colombia, s.p)

Definición que fue modificada por el Acto Legislativo número 3 de 2002, de la siguiente manera:

Los particulares pueden ser investidos transitoriamente de la función de administrar justicia en la condición de jurados en las causas criminales, conciliadores o en la de árbitros habilitados por las partes para proferir fallos en derecho o en equidad, en los términos que determine la ley. (Acto legistivo 03 de 2002 s.p)

inalmente, fue consagrada la amigable composición en los artículos 130,131 y 132 de la Ley 446 de 1998, la cual, entre otros fines, incluye el de "se dictan otras disposiciones sobre descongestión, eficiencia y acceso a la justicia". En desarrollo de tal cometido se tienen los siguientes artículos que hacen mención a la amigable composición:

ARTíCULO 130. DEFINICIÓN. <Incorporado en el Estatuto de los Mecanismos Alternativos de Solución de Conflictos, artículo 223.> La amigable composición es un mecanismo de solución de conflictos, por medio del cual dos o más particulares delegan en un tercero, denominado amigable componedor, la facultad de precisar, con fuerza vinculante para ellas, el estado, las partes y la forma de cumplimiento de un negocio jurídico particular. El amigable componedor podrá ser singular o plural.

ARTÍCULO 131. EFECTOS. <Incorporado en el Estatuto de los Mecanismos Alternativos de Solución de Conflictos, artículo 224.> La decisión del amigable componedor producirá los efectos legales relativos a la transacción. 
ARTÍCULO 132.DESIGNACIÓN. <Incorporado en el Estatuto de los Mecanismos Alternativos de Solución de Conflictos, artículo 225.> Las partes podrán nombrar al amigable componedor directamente o delegar en un tercero la designación. El tercero delegado por las partes para nombrar al amigable componedor puede ser una persona natural o jurídica. (Ley 446 de 1998, s.p)

De la actual definición se puede entender que, tal y como se ha venido desarrollando el concepto, a través de este mecanismo los particulares en conflicto delegan en un tercero una serie de funciones a fin de determinar definitivamente el estado y el cumplimiento de un negocio jurídico que ha dado lugar a la diferencia entre ellas, y que por ende ha sido el objeto que ha dado lugar a la amigable composición.

En relación con los alcances de la amigable composición y su asimilación con la transacción, siguiendo el artículo 2483 del Código Civil, debe indicarse que este método produce los efectos de cosa juzgada y no por ello debe asimilarse o confundirse con la amigable composición en los términos del mismo código. Igualmente, basta indicar que la norma es clara en señalar el modo en el que será escogido el amigable componedor, ya sea singular o plural como tercero encargado y delegado para la solución del conflicto por las partes en discusión; situación que no sucede en la transacción y que hace que estos MASC sean diferentes.

Adicional a lo anterior, se tiene que en materia de contratación administrativa la Ley 80, en su artículo 68, estableció que se podía recurrir a la amigable composición a fin de poder dar solución a las diferencias presentadas durante los contratos entre las partes contratantes, rezando entonces lo siguiente:

ARTíCULO 68.- De la Utilización de Mecanismos de Solución Directa de las Controversias Contractuales. Las entidades a que se refiere el artículo del presente Estatuto y los contratistas buscarán solucionar en forma ágil, rápida y directa las diferencias y discrepancias surgidas de la actividad contractual. Para tal efecto, al surgir las diferencias acudirán al empleo de los mecanismos de solución de controversias contractuales previstos en esta ley y a la conciliación, amigable composición y transacción. Parágrafo. - Los actos administrativos contractuales podrán ser revocados en cualquier tiempo, siempre que sobre ellos no haya recaído sentencia ejecutoriada. ( Ley 80 de 1993, s.p)

Como se puede notar la norma en cita, hace un llamado a las entidades públicas a utilizar los mecanismos alternativos de solución de conflictos, incluyendo la amigable composición, aclarando el legislador que este método buscará solucionar en forma ágil, rápida y directa las diferencias y discrepancias surgidas de la actividad contractual como una medida asertiva y de común acuerdo entre las partes y previa en todo caso a una acción judicial y por lo expuesto diferente a la transacción. 
No obstante, y a pesar de ese importante rol que había ocupado la amigable composición hasta ese entonces, su figura es reforzada por el nuevo estatuto arbitral en Colombia, el cual fue promulgado mediante la Ley 1563 de 2012 y en el cual en su artículo 58 se define este mecanismo así:

ARTíCULO 59. La amigable composición es un mecanismo alternativo de solución de conflictos, por medio del cual, dos o más particulares, un particular y una o más entidades públicas, o varias entidades públicas, o quien desempeñe funciones administrativas, delegan en un tercero, denominado amigable componedor, la facultad de definir, con fuerza vinculante para las partes, una controversia contractual de libre disposición. El amigable componedor podrá ser singular o plural. La amigable composición podrá acordarse mediante cláusula contractual o contrato independiente.

En dicha disposición normativa se elevó la importancia de este método, pues con su uso las partes de una controversia tienen la ventaja de no someterse a un procedimiento judicial e incurrir en altos costos como sucede con la instauración de una acción judicial ante un juez competente o un tribunal arbitral, lo cual entonces evidencia la pertinencia del uso de los MASC como una gran ayuda para la descongestión judicial.

Como resultado de lo anterior, y a título de ejemplo, se indica que para el año 2004 en la Ley 1742 de 2014, mediante la cual se adoptaron medidas y disposiciones para los proyectos de infraestructura de transporte, agua potable y saneamiento básico, para los sectores que requieran expropiación en proyectos de inversión, el legislador hizo una breve alusión a este método como eficiente y eficaz para la solución de conflictos contractuales, garantizando de esta manera el derecho de acceso a la justicia, como entonces se ha tratado de ilustrar en otras áreas del derecho diferentes a las del derecho civil y comercial.

\section{La definición de la amigable composición en Colombia}

Con respecto a la amigable composición es necesario indicar que en la actualidad es uno de los mecanismos alternativos más efectivo, al que pueden acudir los particulares previo al inicio de una acción judicial para dar lo solución a un conflicto, pues como afirma (Bahamón, 2020, p, 25) en este sentido, las partes facultan al amigable componedor para decidir sobre el objeto de la controversia y para que este en todo caso sea quien la dirima.

Por lo expuesto, entonces el amigable tendrá la capacidad de dictar resolución sobre la resolución del conflicto y cuyo pronunciamiento tendrá los mismos efectos que los de la transacción, sin que dicha similitud conlleve a suponer que la amigable composición sea una especie de transacción o la misma transacción, ya que este método es propia e independiente dentro de los MASC. 
Ahora bien, la amigable composición no es, como lo han afirmado algunos Ternera (2006), un contrato de mandato, donde el amigable componedor, un tercero, a través de un contrato de transacción finaliza la controversia de los mandantes, de las partes en conflicto, pues, aunque el amigable componedor actúe como mandatario representando a los mandantes, en la elaboración de la transacción este no ejerce las funciones propias de mandatario, sino de representante de las partes inmersas en la controversia.

La anterior precisión de conformidad a que erróneamente el Consejo de Estado en algunas decisiones ha malinterpretado la representación del amigable componedor, como se cita a continuación:

Se considera importante resaltar, asimismo, que el amigable componedor, como se indicó, interviene como mandatario de las partes que le encargaron la solución de sus diferencias, es decir, actúa en nombre y representación de éstas; por tanto, la decisión que éste profiera la asumen como propia, pues se entiende que el documento que éste emite proviene de cada uno de sus mandantes, razón por la cual dicho documento cumple con uno de los requisitos estatuidos en el artículo 422 del C. G. del P. (C.E., Sección Tercera, Subsección A, Auto 201400652, 23,2017 )

También se encuentran antecedentes de la amigable composición, en las constituciones colombianas, como la de la República de Tunja del 9 de diciembre de 1811, con la "amigable conciliación"; la Constitución de Mariquita del 24 de junio de 1815, con los "jueces menores de paz" y la Constitución de Neiva del 31 de agosto de 1815, con la "amistosa transacción", a instancias de un tercero.

Por consiguiente, la amigable composición en Colombia tiene su base en el principio de la autonomía de la voluntad contractual de las partes (artículo 1602 del Código Civil), y en este sentido, como todo pacto arbitral, tiene dos momentos para su establecimiento: previo al surgimiento del conflicto, llamado cláusula compromisoria; o posterior al surgimiento del conflicto, cuando se denominará compromiso. Siendo entonces, un mecanismo de tipo contractual, que opera mediante representación otorgada al componedor, y que no da lugar a jurisdicción ni proceso, pero su resolución obliga a las partes y produce efectos de cosa juzgada en última instancia.

Con respecto al concepto y naturaleza de la amigable composición, debe señalarse que este MASC es un contrato de mandato especial conforme a los (Arts. 2142, 2156 C.C. y 1262 C.Co.), el cual puede ser civil o comercial (Arts. 2142 C.C. y 1262 C.Co.), singular o plural (Arts. 2152 C.C.) y en donde las partes del contrato de amigable composición son los mandantes, los sujetos del conflicto y el mandatario, el amigable componedor como lo señala (Herboczkovà, 2008. p, 2) en un contexto internacional.

Dentro de las obligaciones y elementos esenciales del mandato de amigable composición, la principal obligación del amigable componedor es la realización de un contrato de 
transacción, por cuenta y a nombre de otros, los mandantes, partes en conflicto. Al ser el convenio de amigable composición un contrato de mandato, se le aplican las normas especiales de la Ley 446 de 1998, las normas del mandato y transacción, la normatividad contractual general y la analogía.

Sin embargo, la amigable composición no comparte todas las obligaciones que derivan de la naturaleza del mandato, pues para el caso del artículo 2158 del C.C., el mandato no confiere más que el poder de efectuar actos de administración, pero en la amigable composición, existe la obligación de efectuar una transacción que vincula a los mandantes y aquí sí se incluyen actos de disposición (artículo 2470 C.C.).

Al no ejercer actos de administración sobre los bienes de los mandantes, el amigable componedor no tendría que rendir cuentas sobre su administración, y al no detentar bien alguna propiedad de aquellos, tampoco podría ejercitar el derecho de retención, ni se le aplicaría lo dispuesto en los artículos 2179 y 2182 del Código Civil, sobre el riesgo por pérdida de especies metálicas e intereses debidos al mandante, respectivamente.

Al ser el contrato de amigable composición, un contrato intuito personae Leal, Pérez (2017, P.13), sostiene que no es posible que el amigable componedor delegue su encargo como lo permite el artículo 2161 del C.C., es un contrato intuito personae, pues las calidades del amigable componedor son las que constituyen su causa principal. Si se trata de varios amigables componedores, estos al tenor de los artículos 2153 del C.C. y 1272 del C.Co. deben realizar su encargo conjuntamente.

Respecto a la responsabilidad del amigable componedor como mandatario, si las partes en conflicto, los mandantes, le proveen de lo necesario para la ejecución de su encargo, su obligación no será de medios, sino de resultado, pues para liberarse de su responsabilidad deberá efectuar la transacción prometida o la prueba de una causa extraña. Igualmente, parte de las obligaciones derivadas de la naturaleza del contrato de mandato, se aplican a la amigable composición, como las obligaciones del mandante (Art. 2184 del C.C.) y las causales de terminación del contrato (Art. 2189 del C.C.). Además, la obligación impuesta al mandatario debe cumplir los términos del mandato (Art. 2157 C.C.).

En este sentido la responsabilidad del amigable componedor sería similar al arbitramento, aunque según Rey, Vallejo (2016)el mismo en la amigable composición no ejerce funciones jurisdiccionales como si lo hace el árbitro, siendo la amigable composición más flexible al no estar sometida a procedimiento alguno, como sí ocurre con el arbitramento, que puede ser en derecho, institucional e independiente.

En otro sentido y reafirmando la posición de asemejar la amigable composición a un mandato: debe indicarse que para que el amigable componedor cumpla con la transacción acordada, debe acatar los términos del contrato de mandato de amigable composición 
(Arts. 2157 C.C. y 1263 C.Co.) y, consultar los vínculos entre sus mandantes relacionados con el conflicto, debe apoyarse en las prácticas o usos comunes de las actividades de los mandantes y evitar cualquier acto que perjudique a una o a todas las partes.

A falta de estipulación de los mandantes sobre la ejecución del contrato, se deberá aplicar la Ley 446 de 1998, el régimen del mandato (Arts. 2142 y siguientes del C.C. y Arts. 1262 y siguientes del C.Co. .), el régimen de la transacción (Arts. 2469 y siguientes del C.C. y Arts 340 siguientes del C. de P.C.), normas generales de contratos del Código Civil y de Comercio, junto con el Decreto 1818 de 1998 y la Ley 640 de 2001, normatividad de los mecanismos alternativos de solución de conflictos.

Se puede decir que para este autor contrato de amigable composición también podría ser visto como un mecanismo de solución de conflictos autocompositivo, pues la transacción que vincula directamente a los mandantes es adoptada por el amigable componedor al representarlas. En un sentido similar, de acuerdo con Lezcano (2011 ) la amigable composición no es más que un modo de transacción que incluye a un tercero mandatario, dado que en esencia el objeto de la transacción es el mismo que el de la amigable composición: terminar o evitar un litigio.

Igualmente, el amigable componedor es un mandatario con representación, pues recibe el encargo de realizar un acto jurídico a nombre de otros. Es decir, está de acuerdo con la tesis anterior que afirma que se trata de un mandato con varios mandantes. El acto para realizar sería el acuerdo transaccional, por supuesto; y el resultado sería una solución contractual del problema; pues no se entiende que la amigable composición sea una actuación judicial, pues no se asemeja a un laudo arbitral ni a la conciliación.

Sin embargo, se cree que el único efecto de similitud con la transacción es el de vincular obligatoriamente a las partes cuando, como ya se afirmó, produce los efectos de cosa juzgada. Razón por la cual podría pensarse, que la figura representa una transacción realizada por mandatarios con representación, cumpliendo el encargo de ambas partes de decidir sobre el conflicto.

Por lo expuesto y dentro de sus características generales esta figura posee un esquema mixto, puesto que las partes eligen un tercero que decida sobre el conflicto, pero a la vez están comprometiendo su voluntad, al conferir un mandato al componedor para ello. Una vez se soluciona el conflicto por parte del componedor se dice que se está heterocomponiendo.

Ahora bien, la decisión del componedor no constituye sentencia; tema que valdría la pena estudiar dado que, como ya se explicó , produce el mismo efecto de cosa juzgada en última instancia que produce la transacción. Por ende, la naturaleza jurídica de este método de solución de conflictos en el hecho de la voluntad de las partes (sin duda un 
elemento esencial), declarándolo un contrato o convención, es decir que el resultado del proceso es el de un contrato, por lo tanto, no se asemeja a una sentencia como en el caso del laudo arbitral.

Desprendiéndose del artículo 130 de la Ley 446, la amigable composición consta de ciertas características elementales, las cuales son:

- "Delegación que hacen dos o más particulares.

- Se realiza en un tercero, denominado amigable componedor -podrá ser singular o plural.

- Puede precisar con fuerza vinculante para ellas y con los mismos efectos legales de la transacción,

- El estado de las cosas, las partes y la forma de cumplimiento de un negocio jurídico.

- Es escogido por las partes, o éstas delegan tal función en un tercero" (Ley 130 de la Ley 446, s.p)

Considerándose las características de la Ley 446 entonces, la amigable composición trata de un acto y/o negocio jurídico de naturaleza contractual, derivado de la voluntad de las partes, lo cual en cierta medida lo diferencia del arbitramento que según, Fuentes \& Hernández ( 2019) el cual a pesar de ser un método alternativo para la solución de conflictos es un procedimiento judicial en el cual, al igual que en la amigable composición se encuentra la voluntad de las partes de someter su discusión a un particular en lugar de acudir a la jurisdicción ordinaria. Diferenciación que entonces posiciona a la amigable composición como un método y acto complejo debido al número de personas intervinientes, pues existen dos momentos: el pacto o convenio en el cual las partes delegan a un tercero la solución de la controversia; y otro cuando se produce la resolución que da fin al problema.

El Consejo de Estado, por su parte en la Sala de lo Contencioso Administrativo, Sección Tercera, el 6 de febrero de 1998, mediante el consejero ponente: Daniel Suárez Hernández; definió este método como: "Una transacción lograda a través de terceros con facultades para comprometer contractualmente a las partes". (Consejo de Estado, Sala de lo Contencioso Administrativo, Sección Tercera, Sentencia 6 de febrero de 1998 s.p).Es decir, que los únicos mecanismos que operarían como procedimientos judiciales serían el arbitramento y la conciliación (según su interpretación) ( Sentencia C-330 de 2000).

Ahora bien. según lo estudiado a lo largo de este apartado, se ha visto que no hay posibilidad de que la amigable composición sea constituida como un mandato, puesto 
que no opera como tal. Para empezar el mandato: "Es un contrato en el cual una persona confía la gestión de uno o más negocios a otra, que se hace cargo de ellos por cuenta y riesgo de la primera." (Artículo 2142 del C.C.).

Como se puede ver en el caso de la amigable composición, el componedor si bien realiza una tarea encomendada, ha sido encargada por varias partes, aparte de que no obra a cuenta y riesgo de estas, puesto que es neutral, autónomo y no sigue instrucciones de ningún mandante en sus resultados, puesto que decidirá lo que mejor tenga.

Además, podrá decidir en contra de alguna de las partes, caso en el cual afectaría los intereses de aquel que supuestamente encomendó la tarea. A este punto debe indicarse que referente a la responsabilidad el mandatario en este método responde por la culpa leve según lo dicho en el artículo 2155 del Código Civil. Mientras, que por su parte el componedor solo responderá por el daño ocasionado directamente a una de las partes.

En el mismo sentido, el amigable componedor no cumple un informe de su gestión en los términos del artículo 2181 del Código Civil colombiano a fin de cobrar su comisión, su deber es el de realizar su labor en la mayor de las diligencias. Adicionalmente, el mandato tiene restricciones claras, mientras que el poder dado al amigable componedor se entiende dado para realizar la labor de dictar resolución respecto al problema como mejor lo tenga a bien. Igualmente, de acuerdo con lo establecido tanto en el artículo 2189 del Código Civil, como en el 1279 del Código de Comercio, el mandato es revocable, mientras que las facultades depositadas en el amigable componedor no lo son.

Por todas estas razones, no es posible afirmar entonces, como lo hacen los autores citados que la naturaleza de la amigable composición que esta sea un mandato, más aún si hablamos de mandato sin representación, en el cual mandatario actúa como si lo hiciese a nombre propio sin la obligación de informar a terceros sobre la condición de su actuación a favor de otro.

\section{El papel del amigable componedor}

Para abordar el tema referente a la persona que debe realizar el trabajo de amigable componedor, el artículo 132 de la Ley 446 reza lo siguiente:

Las partes podrán nombrar al amigable componedor directamente o delegar en un tercero la designación. El tercero delegado por la parte para nombrar al amigable componedor puede ser una persona natural o jurídica. (Ley 446 de 1998, s.p)

Hay que mencionar además a lo dispuesto por el legislador que las principales características del amigable componedor según Lezcano las siguientes: 
- Es una delegación que realizada por dos o más personas (las que están inmersas en el conflicto).

- El tercero denominado amigable componedor es quien da la solución y puede ser singular o plural.

- La decisión del amigable componedor tiene fuerza vinculante para las partes.

- Las partes pueden realizar la elección del amigable componedor o delegar esta atribución a un tercero. (Lezcano, 2011, p. 517-519)

En lo que toca a estas características generales, puede establecerse que las partes de una controversia tienen la potestad en la designación de un tercero para la solución del conflicto por el método alternativo que elijan para la resolución de la controversia. Aunque puede resultar dicha potestad un problema dado que obtener el mutuo acuerdo de las partes en controversia es una gran labor como también puede serlo decidir un tercero que elija a otro tercero que solucione el problema. De allí, que las partes pueden designar al amigable componedor directamente, o pueden confiar su designación en un tercero, quien podrá ser persona natural o jurídica (Art. 132 de la Ley 446 de 1998).

Por consiguiente, el amigable componedor debe ser legalmente capaz, no requiriéndose entonces para tal efecto que el mismo sea abogado, como ocurre para la conciliación y el arbitraje en derecho, por lo que este puede ser una persona natural o jurídica, ya que su labor consistirá en resolver la controversia desde una obligación de resultado en la cual la composición debe llegar a un feliz término. De este modo, no es posible que se produzca un nuevo proceso luego de llevar a cabo la amigable composición, ya que el componedor debe dar una respuesta.

Al respecto Ternero (2006) ha indicado que el deber del amigable componedor debe centrarse en representar los intereses en conflicto, pues en últimas es quien actúa por cuenta y representación de las partes, esta surge sin necesidad de poder otorgado por separado, pues el apoderamiento deriva del mismo contrato de amigable composición (Arts. 130, 131 Ley 446 de 1998).

De manera que las obligaciones del amigable componedor serán efectuar el contrato de transacción vinculante para las partes y abstenerse de efectuar un acuerdo perjudicial para ellas. Respecto a la primera, una vez configurado el contrato, el amigable componedor debe buscar la mejor fórmula de arreglo para el conflicto de sus mandantes, el cual será objeto de la futura transacción, para lo cual deberá seguir sus instrucciones, pues como se ha dicho, desde que estos le provean lo necesario para cumplir su misión, el amigable componedor deberá cumplir con la transacción prometida, pues su obligación será de resultado y no de medio, no pudiendo este encargar a otro su gestión, salvo expresa autorización. 
En relación con la segunda de las obligaciones del amigable componedor, la transacción propuesta no debe ir contra los intereses de uno o varios de los mandantes, o implicar sacrificios para uno solo, pues esta debe implicar cargas equivalentes para todos ellos, por lo que su discrecionalidad debe ser imparcial y en búsqueda de la solución a la controversia en cumplimiento de las obligaciones mencionadas.

\section{El papel de las partes en la amigable composición}

Adicional a lo anterior, debe señalarse que las partes que acudan a este medio sean plenamente capaces y conscientes, pues en general y al igual que en otros casos y procesos judiciales como extrajudiciales, es esencial para poder solicitar, iniciar y actuar en cualquier tipo de arreglo o acción judicial la capacidad y legitimación.

En cuanto a la legitimación se debe señalar que esta: "Implica la capacidad del sistema para Engendrar y mantener la creencia de que las instituciones políticas existentes son las más apropiadas para la sociedad" (Lipset, 1988, p. 67), por lo tanto, en este orden de ideas, quien estará legitimado será quien sea capaz conforme a la ley.

Con respecto a la capacidad, se utilizan las mismas reglas que se aplican en todos los demás casos y en todo proceso. Así, aquel que solicita, o acude a la amigable composición debe ser capaz, siguiendo lo dicho en el artículo 2470 del Código Civil: "No puede transigir sino la persona capaz de disponer de los objetos comprendidos en la transacción." (Código Civil, s.p) Entonces se podría dar lugar a dos tipos de nulidades: uno por incapacidad de la parte que recurre a la amigable composición, que podríamos concluir sería relativa, y otra derivada de la no capacidad de disponer del objeto de la composición, o absoluta.

Para la primera, aparte de los incapaces (para lo cual es necesario ceñirse a lo mismo que a la capacidad para contratar) se debe aclarar que aquel que tiene mandato, requiere poder especial para transigir. Esto incluye al abogado que aun pudiendo estar facultado para actuar en juicio por la misma causa, no podrá transigir sin el poder especial para hacerlo. Con respecto a la segunda se da por entendido que nadie puede disponer de más de lo que le es propio.

En cambio, sobre las obligaciones de los mandantes respecto al amigable componedor, están las de pagar su remuneración y proveerlo de lo necesario para que realice la transacción. Respecto a la remuneración, el numeral 3 del artículo 2184 del C.C. Y el artículo 1264 del C.Co., remiten a prácticas o usos propios del respectivo tipo de actividades para su determinación. Al ser remunerados métodos alternativos para la solución de conflictos por disposición del legislador, ello implica que la amigable composición como MASC también lo sea, remuneración que podrá ser establecida por las partes, el juez o peritos, como lo permiten el artículo 2143 del C.C. Y el artículo 1264 del C.Co. El incumplimiento de los mandantes de la segunda obligación a su cargo 
implica eximente de responsabilidad para el amigable componedor, si este incumple con la transacción encomendada, debido a no habérsele suministrado lo necesario para ello.

\section{Resultados}

La no procedencia de la amigable composición

Acorde con lo dispuesto por el legislador en el Código Civil, se ha identificado que la amigable composición no es procedente en las siguientes situaciones:

- Art. 2473.-No se puede transigir sobre el estado civil de las personas en tanto comprenda los alimentos futuros que se deban a determinadas personas no serán válidas sin la aprobación judicial, y éste deberá ceñirse lo establecido en la Ley.

- Art. 2475.- No vale la transacción sobre derechos ajenos o sobre derechos que no existen. Lógicamente no se puede decidir sobre lo que compete a otros, y todo objeto de negocio jurídico debe existir o ser probable, en este caso necesariamente debe ser cosa cierta y presente.

- Art. 2476.- Es nula en todas sus partes la transacción obtenida por títulos falsificados, y en general por dolo o violencia. Este punto está referido a una nulidad por causa ilícita.

- Art. 2477.- Es nula en todas sus partes la transacción celebrada en consideración a un título nulo, a menos que las partes hayan tratado expresamente sobre la nulidad del título. En este caso estamos referidos a objeto nulo.

Art. 2478.- Es nula asimismo la transacción, si, al tiempo de celebrarse, estuviere ya terminado el litigio por sentencia pasada en autoridad de cosa juzgada, y de que las partes o alguna de ellas no haya tenido conocimiento al tiempo de transigir. Lógicamente en caso de que exista sentencia no habrá lugar a transigir sobre un proceso ya terminado. (Código Civil, s.p)

De las anteriores prohibiciones, se infiere que para acudir a la amigable composición se debe tener la posibilidad de transigir el asunto en particular sobre el mismo momento y en dicho momento, este no debe versar sobre objeto ilícito o sobre materia de derecho público.

En este sentido se ha rectificado conforme a lo dispuesto por el legislador, que a través de este método es permitido transigir para subsanar errores en los contratos, aun cuando existen nulidades. En derecho mercantil las partes pueden sanear nulidades, ya sea por figuras como la prescripción o la ratificación de las partes utilizando alguno de los métodos alternativos para la solución de conflictos o por el simple mutuo acuerdo, por ejemplo, en lo relativo a las sociedades y al contrato societario cuando se ocasiona una nulidad relativa, vía la prescripción o la ratificación de las partes. (Art 108 Código de Comercio) 
Existen aun así las prohibiciones sobre transar sobre derechos a terceros, y en general diremos que cuando el objeto de la amigable composición verse sobre derechos ajenos será nula y podrá solicitarse su nulidad por parte de quien se ha visto afectado por parte de esta. Esto lleva a concluir que sobre la decisión del amigable componedor cabe lugar la demanda de nulidad (en un símil con lo propio para el laudo arbitral). En este punto en específico se remite al artículo 2484 del Código Civil, en el cual se afirma que lo transado no tiene efectos frente a terceros, es decir, que todo aquel que resulte afectado tendrá acción para solicitar su reparación.

En definitiva, habrá nulidad por objeto y causa ilícitos, no obstante, las nulidades relativas por las partes, y de hecho es la amigable composición el mecanismo idóneo para que se lleven a cabo tales saneamientos, así mismo, no sobra repetir que se debe poseer poder y capacidad sobre el objeto a decidir en la amigable composición, de lo contrario será nula.

\section{El procedimiento de la amigable composición}

Teniendo en cuenta la naturaleza de la amigable composición, al ser un (MASC) que no presenta solemnidades o requisitos en cuanto a su desarrollo conforme con los artículos 131, 132 y 133 de la Ley 446 de1998, tiene como principales etapas las siguientes:

Una audiencia de apertura, donde se reconozca al amigable componedor como actor dirimente del conflicto entre las partes, y en esta deberá establecerse el alcance, objeto y carácter de la controversia, su duración y el desarrollo de las demás etapas posteriores, la naturaleza de la disputa y, debe ser esta la oportunidad para persuadir a los participantes en el conflicto a que presenten los elementos de juicio y pruebas que pretendan hacer valer durante el trámite de la amigable composición.

Es apenas natural, que sea la primera audiencia la que permita, fijar las partes, el objeto del litigio, y pruebas a aportar, aquí surge el interrogante de si el amigable componedor podrá practicar pruebas, como ocurre en el arbitramento o si por el contrario solo podrá limitarse a la valoración de las legalmente aportadas a la controversia por las partes, aplicando las normas y principios establecidos en el Código de Procedimiento Civil y demás normas que regulen la apreciación probatoria.

Con respecto a lo anterior, debe considerarse que el amigable componedor no ha sido investido por las partes como ocurre con el arbitraje y la conciliación de facultades jurisdiccionales, por lo que no le será posible el decreto y práctica de pruebas y tan solo habrá lugar a que valore las ya existentes y aportadas por los sujetos de la controversia, en aras de resolver, componer el conflicto presentado. 
Igualmente, en esta audiencia se deberá indicar el monto de los honorarios, el porcentaje de los mismos, por lo que se ha llegado a cuestionar, ¿qué sucede en el evento de que una de las partes no proceda a su pago?, y, por otra parte, ¿qué sucederá si ninguna de las partes proceda al pago de los honorarios del amigable componedor? En el primer escenario, se infiere que como sucede en el arbitramento una de las partes podrá pagar por la otra y luego repetir contra esta y en el evento del no pago por ninguna, se entenderá que el amigable componedor estará exonerado de su gestión, aunque nada impide que la composición sea gratuita.

En esta primera audiencia se deberá establecer si el amigable componedor resolverá la controversia en derecho, equidad o en criterios técnicos. También será esta la oportunidad de pactar cláusulas penales y de confidencialidad, por lo que llego a cuestionarse, ¿si podrá hacerse responsable al amigable componedor en caso de que incumpla su gestión?, pregunta que bajo un criterio objetivo podría ser afirmativa, pues la amigable composición como acuerdo de voluntades, obligaría también al amigable componedor en caso de pactarse cláusula penal para su incumplimiento y no solo dicho postulado sería aplicado a las partes, pues aunque el amigable componedor incumpla su deber de guardar confidencialidad sobre el asunto encargado, las partes pueden repetir contra él y sobre la resolución de la controversia, por lo que el amigable componedor puede llegar a ser susceptible de responsabilidad.

Posteriormente, vendrá una fase de investigación que le permitirá al amigable componedor determinar y estudiar el problema, analizar documentos y demás pruebas, indagar a terceros y a las mismas partes para lograr establecer su propio juicio y de esta forma aprehender la controversia.

La última etapa será la audiencia de decisión, en la cual el amigable componedor presenta la solución a las partes, que, dada la simplicidad de este mecanismo, podría darse a conocer de manera verbal a los contendientes, aunque en la practica el amigable componedor notifique dicha decisión por escrito, conforme a las costumbres y prácticas en este método. En dicha decisión, constará la firma de las partes en controversia para que esta sea vinculante para las partes y oponible, junto con la firma del amigable componedor.

Ahora bien, es importante indicar que:

(...) el acuerdo al cual se llega, y además toda la información que se transmita entre las partes y desde ellas hacia los amigables componedores, debe quedar protegida por el principio de confidencialidad que compromete a los amigables componedores a mantener en reserva la información suministrada por los interesados, así como el acuerdo final elaborado por ellos mismos (...). (Mojica, Cortes, 2008, p. 49-62 ) 
Criterio de confidencialidad que entonces nos lleva a concluir que la amigable composición en su procedimiento otorga beneficios de eficiencia, eficiencia y celeridad para la resolución de una controversia, con unas reglas claras aplicar para su procedimiento, pues en caso contrario las partes interesadas en transar sus desacuerdos se encontrarían en una posición indefensa, pues existirá un abuso de control de ejercicio de las atribuciones del amigable componedor y estas quedarían supeditadas a sus atribuciones sin fundamento legal alguno, lo cual por las razones antes expuestas se evita con la realización del procedimiento descrito por los artículos 131, 132 y 133 de la ley 446 de1998 y en algunos casos con las normas del Código General del Proceso.

\section{La amigable composición como un (MASC) que facilita el acceso a la justicia}

Contando hasta este momento con una fundamentación teórica sobre el derecho al acceso a la administración de justicia, los MASC y a profundidad la amigable composición es pertinente señalar si dicho mecanismo incide en la materialización del derecho al acceso a la justicia para lo cual es importante considerar que en términos generales:

La garantía constitucional de acceso a la justicia no significa que todas las disputas entre los particulares deban ser resueltas por los jueces, pues precisamente el artículo 116 de la Carta garantiza la existencia de mecanismos alternativos de solución de conflictos, como la conciliación o el arbitraje, los cuales pueden ser ampliados por el Legislador. Al respecto, la corte Constitucional ha dicho que "es competencia del legislador, de acuerdo con los parámetros que determine la Carta Política, el fijar las formas de composición de los conflictos judiciales, los cuales -no sobra aclararlo- no siempre implican el ejercicio de la administración de justicia. (Sentencia C-163/99, 1999)

Destacando de esa forma la importancia de los MASC, ya que coadyuvan a generar un mayor acceso a la justicia, pues así mismo la sentencia C-1195/01, documentó dos años más tarde sobre el hecho que:

El derecho a acceder a la justicia guarda estrecha relación con el derecho al recurso judicial efectivo como garantía necesaria para asegurar la efectividad de los derechos, como quiera que "no es posible el cumplimiento de las garantías sustanciales y de las formas procesales establecidas por el Legislador $\sin$ que se garantice adecuadamente dicho acceso (Sentencia C-1195/01, 2001, s.p)

Es de gran importancia la relación que resalta la Corte Constitucional en la sentencia citada, puesto que establece que el derecho al acceso a la justicia no solo se encamina a poder iniciar una determinada actuación procesal, sino que conduzca a efectivizar la satisfacción de un derecho, para lo cual, los MASC y entre aquellos la amigable composición se constituyen como métodos de gran ayuda para la administración de justicia, pues estos además de evitar la descongestión judicial facilitan que los conflictos sean solucionados de manera célere y efectiva. 
Bajo esa perspectiva se puede vislumbrar a todas luces que la amigable composición se configura como un mecanismo alternativo de solución de conflictos, expedito, idóneo y bastante completo para fortalecer el acceso a la administración de justicia toda vez que se constituye como un escenario adecuado para que dos partes en conflicto propendan por llegar a una solución amigable sin que tengan que acudir necesariamente ante la ya congestionada, paquidérmica y patológica jurisdicción ordinaria, logrando así dirimir sus conflictos al mismo tiempo en que se generan acuerdos y efectos vinculantes para las partes.

\section{Conclusiones}

Con fundamento en todo lo anterior, debe señalarse que la amigable composición se encamina principalmente a la resolución de conflictos que pueden ser solucionados de común acuerdo y sin que necesariamente medie la intervención de los funcionarios del Estado, lo cual indica que este MASC facilita el acceso a la justicia, pues esa se constituye como uno de los pilares, no solo del Estado de derecho, sino de la misma sociedad, el cual se ha ido fortalecido gracias a fenómenos como la congestión judicial y la búsqueda de las partes en una controversia de buscar una solución de forma más especializada.

Lo anterior, se fundamenta principalmente en la obtención de soluciones a los conflictos que surgen entre los ciudadanos, bien sea por la vía tradicional e institucional, jurisdicción o por los MASC, y entre ellos la amigable composición, el cual resolviendo de manera civilizada e imparcial las diferencias suscitadas en la sociedad, ayuda a prevenir y proteger los derechos plenamente identificados para cada individuo como son la dignidad y el respeto de sus garantías, de tal forma que al garantizarse la justicia, se construya una sociedad fundamentada en el orden y la armonía social que no solo permita hacer efectivos los derechos consagrados en la Carta Política de 1991, sino en las disposiciones del legislador en el derecho sustancial

Bajo ese contexto de justicia de común acuerdo, se indica que la Constitución Política de 1991, además, de consagrar los derechos subjetivos y fundamentales de los ciudadanos, promovió los MASC y la amigable composición como un refuerzo para el acceso a la justicia, al otorgarle funciones jurisdiccionales temporales a particulares tendientes a la superación de conflictos como el amigable componedor, basándose en la participación ciudadana a través de factores que rigen el comportamiento de la comunidad, lo que resulta en la colaboración de las partes en la solución del conflicto, sin necesidad de acudir ante instancias judiciales. 


\section{Referencias}

Ángel, Guarnizo , L. K. (2016). Autonomía de la voluntad ¿Decadencia o auge? Verba luris, 71-91.

Bahamón, Oviedo, A. (2020 ). Baseball arbitration desde una perspectiva contractual . Estudios Socio-Juridicos , 1-32.

C.E., Sección Tercera, Subsección A, Auto 2014- 00652, 23 , Auto 2014- 00652, (Consejo de Estado 23 de marzo de 2017).

Fuentes Mancipe, M., \& Hernandez, Rodriguez , I. (2019). El principio de la autonomía de la voluntad contractual vs el control jurisdiccional constitucional en los laudos arbitrales. Revista E-Mercatoria, Vol. 18, No. 1, enero-junio 2019. Obtenido de https://ssrn.com/abstract=3550137

Gierke, O.(1995). Teorías políticas de la edad media; estudio preliminar Benigno Pendás; Madrid: Editorial: Centro de Estudios Constitucionales,. Págs. 143 y 144.

Herboczkovà, J. (enero de 01 de 2008). AMIABLE COMPOSITION IN THE INTERNATIONAL. Obtenido de The Masaryk University,: https://is.muni.cz/el/1422/jaro2008/ EL002/um/5635138/5635141/herboczkova_jana.pdf

Hernández , F. K., \& Guerra , C. D. (2012). El principio de autonomía de la voluntad contractual civil. Sus límites y limitaciones. Revista jurídica de investigación e innovación educativa, 27-46.

Lezcano, Miranda, M. E. (2011). La justicia de todos : mecanismos alternativos de solución de conflictos. Medellin: Fundación Universitaria Luis Amigó,.

Leal. Pérez., H. (2017). Manual de contratos . Bogota: Leyer .

Lipset, S. M. (1987). No hay ningún eBook disponible. Buenos, Aires: Eudeba .

Mojica, Cortés, P. F. (2008). Elementos para el diseño de un trámite de amigable composición en la solución de controversias contractuales entre particulares. Via luris , 49- 62.Rey, Vallejo, P. (2016). El arbitraje domestico Colobiano la sobra de la amigable compocision como mecanismo que privilegia La autonomia de la Volntad. Vuniversitas , 227-270.

Sentencia C-163/99 , Expediente D-2169 (Corte Constitucional , Mp, Alejandro Martinez Caballero 17 de Marzo de 1999).

Sentencia C-330 de 2000, expediente D-2504 (Corte Constitucional, MP. Carlos Gaviria Diaz 22 de Marzo de 2000). 
Sentencia C-1195/01, Expediente D-3519 (Corte Constitucional 15 de Noviembre de 2001).

Ternera, F. (2006 ). Amigable Composición: un contrato para solucionar conflictos.-- . Revista de Derecho Privado, , 3-17. 